\title{
REVIEW \\ MRI in acute and subacute post-traumatic spinal cord injury: pictorial review
}

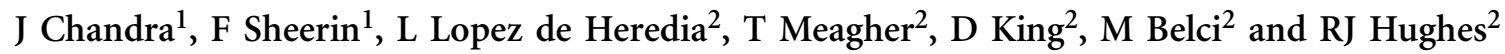

Study design: Pictorial review.

Objectives: To illustrate MRI signs of acute and subacute injury with emphasis on evidence-based links to clinical outcome and implications for treatment.

Methods: Description of important aspects of MRI techniques and illustration of critical MRI signs important in the assessment of spinal cord injury following trauma, in the acute and subacute stages.

Conclusions: Familiarity with cord MRI appearances has an important impact on planning the management of the acutely spinal cord injured patient and also identifying complications in the subacute phase particularly in the presence of neurological deterioration. Spinal Cord (2012) 50, 2-7; doi:10.1038/sc.2011.107; published online 8 November 2011

Keywords: MRI; imaging; spinal cord injury; cord compression; cord oedema; subacute progressive ascending myelopathy

\section{INTRODUCTION}

The role of magnetic resonance imaging (MRI) in evaluating the acutely injured spine is well-established, and contributes to assessment of vertebral injury, ligamentous disruption, associated disc protrusion as well as the exact site of maximal canal stenosis and nature of the cord injury. Clinical scoring using the American Spinal Injury Association Impairment scale remains the best predictor of outcome in the acute setting, ${ }^{1}$ but there are strong predictors from certain imaging appearances. The presence of cord haematoma and/or cord oedema provides information regarding the severity and extent of the injury and these features may help clinicians to predict functional recovery. ${ }^{2-5}$ As new promising strategies in spinal cord injury (SCI) therapy emerge, advances in neuroimaging including greater use of diffusion-weighted imaging and functional MRI techniques may have a greater role in determining initial management.

Many of the descriptive terms used in the spinal cord imaging literature have been agreed on, though contusion is used variably. Some authors comment only on cord haemorrhage or haematoma. In view of reports of different outcomes, we use the terms haemorrhagic contusion and cord haematoma to distinguish these imaging signs.

In this review article, we outline MRI signs in both the acute and subacute period of SCI. We also consider a rationale for imaging technique to maximise diagnostic information in this group of patients.

\section{MR TECHNIQUE}

Most patients will require both MRI and computed tomography in the initial assessment of traumatic SCI. In this clinical situation, there is an advantage in performing MRI as the initial complex imaging as it can guide the extent of the computed tomography examination. Noncontiguous remote vertebral injury occurs in around 6 to $34 \%$ of cases, ${ }^{6}$ and for this reason a sagittal T2-weighted fat-supressed wholespine study is indicated in spinal trauma. Efforts should be made within reason to limit the field of computed tomography (and thus radiation dose) in this relatively young population.

Assessment of the whole spine in traumatic cord injury is important. For this, we use a large field of view $(350 \mathrm{~mm})$ and sagittal Short Tau Inversion Recovery (TR 3500, TE 74), a type of T2-weighted fatsupressed sequence, followed by a smaller field of view $(280 \mathrm{~mm})$ of the primary injury site with sagittal fast spin echo T1-weighted (T1W) (TR 535, TE 108), fast spin echo T2-weighted (T2W) (TR 3500, TE 108) and axial gradient echo T2*-weighted (T2^W GRE) (TR 490, TE 20, flip angle 30) sequences of the injured cord. The gradient echo sequence is important to look for susceptibility effect from cord haemorrhage or haematoma.

New techniques that are becoming available include diffusionweighted imaging. This is challenging to perform in the cord compared with brain imaging, but on more modern systems it can provide useful results. ${ }^{7}$ It may be particularly useful in the clinical context of abnormal neurology and normal standard MR sequences when it may demonstrate diffusion restriction as a marker of previously occult cord injury. $^{8-10}$

In the subacute period, many patients will have spinal fixation and the clinical question is more commonly related to post-operative infection, post-operative bleeding and cause for ascending neurology or pain. Artefact from spinal fixation constructs has traditionally limited the information available from MRI in this situation. However, careful sequence choice with fast spin echo sequences, Short Tau Inversion Recovery acquisitions and high bandwidth can usually provide excellent images, particularly if fixation with titanium devices has been employed (Figure 1). In our practice, our spinal 'metal artefact reduction' protocol comprises sagittal Short Tau Inversion

${ }^{1}$ Department of Neuroradiology, John Radcliffe Hospital, Oxford, UK and ${ }^{2}$ National Spinal Injuries Centre, Stoke Mandeville Hospital, Buckinghamshire Healthcare Trust, Aylesbury, UK

Correspondence: Dr RJ Hughes, Department of Radiology, National Spinal Injuries Centre, Stoke Mandeville Hospital, Mandeville Road, Aylesbury HP218AL, UK. E-mail: richard.hughes@buckshealthcare.nhs.uk

Received 13 May 2011; revised 25 July 2011; accepted 26 July 2011; published online 8 November 2011 

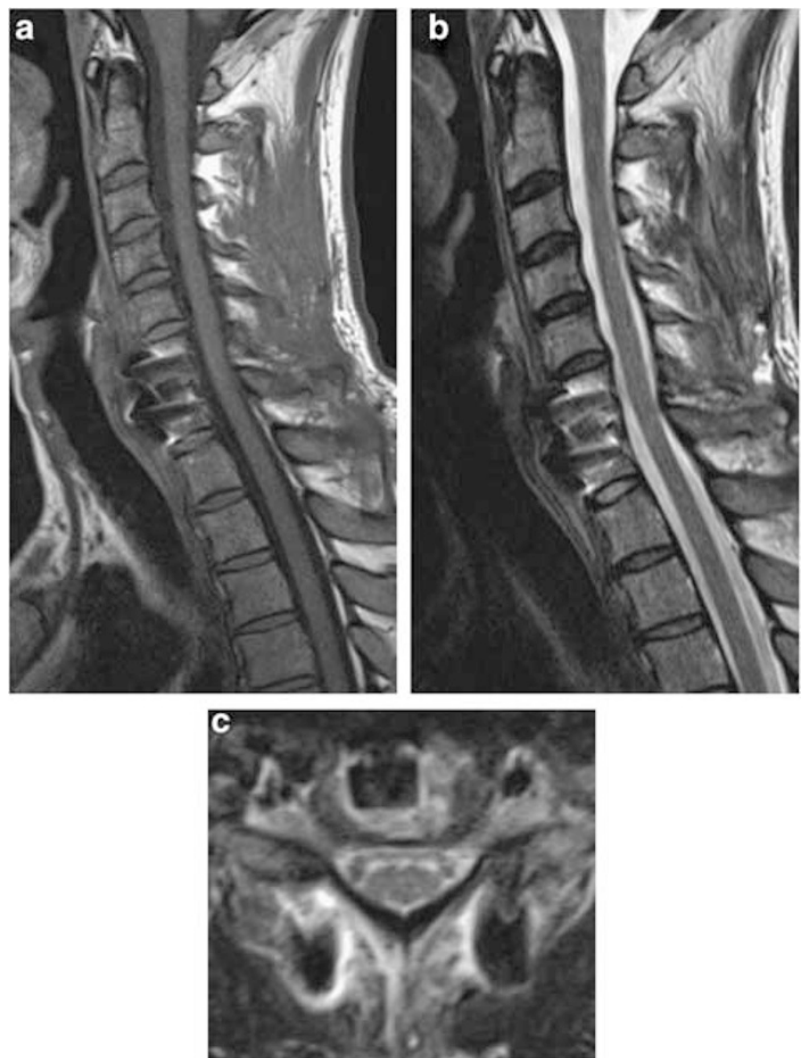

Figure 1 Metal artefact. This patient had anterior and posterior fixation for fracture at $\mathrm{C6} / 7$. Scans have been acquired with high-bandwidth imaging sagittal T1W (a), T2W (b) and axial T2W fast spin echo (c) sequences. Note the minimal artefact only. The spinal canal and cord are well-demonstrated.

Recovery (FOV 280 mm, bandwidth 391, TR 4000, TE 42), T1W (FOV $280 \mathrm{~mm}$, BW 434, TR512, TE 13), T2W (FOV $280 \mathrm{~mm}$, TR5120, TE110) and axial T2W (BW 434, TR5120, TE 110). It is less important to image the whole spine in the subacute period, and targeted high-resolution sagittal T1W, T2W and axial images relating to the injury will usually suffice.

\section{ACUTE CORD INJURY}

There is a spectrum of changes of the acutely injured cord on MRI from concussion, which is invisible on imaging, via cord oedema, haemorrhagic contusion and cord haematoma to complete transection. The radiological-pathological correlation of the use of MRI in SCI is supported by animal and post-mortem studies and provides a good evidence base for its use as a proxy by clinicians to determine where on the spectrum of injury severity the patient lies. ${ }^{11-13}$

\section{Cord concussion}

The most favourable outcome is seen in acute SCI patients, where the cord itself appears normal on standard T1W and T2W MRI sequences. ${ }^{14,15}$ Shimada et al. ${ }^{15}$ reported on this pattern in 10 out of 75 patients, 9 of whom had no bone injury. Symptoms in this group almost completely resolved in two months (Figure 2).

\section{Cord compression}

There is a direct relation between the degree of maximum cord compression, acute neurological deficit and functional independence measure at discharge. ${ }^{2,16}$ Estimation of percentage of compression is calculated by comparison with segments above and below the injured
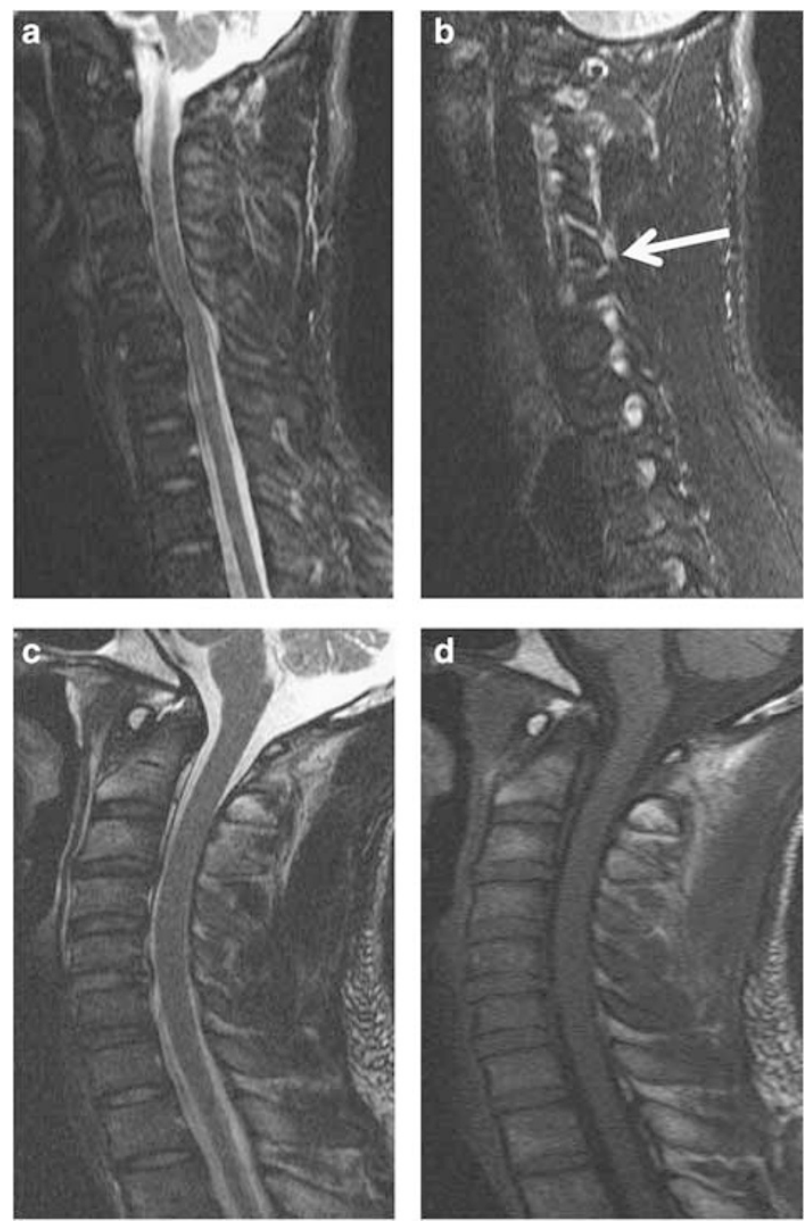

Figure 2 Cord concussion with normal MRI fast spin echo cord signal. This rugby player became tetraplegic at the base of a collapsed scrum. (a) The initial sagittal T2W image demonstrates normal cord signal and a vertebral step due to a unilateral facet dislocation, better seen on (b) a parasagittal T2W image (open white arrow). (c) Post-reduction T2W and (d) T1W images again demonstrate no signal abnormality within the cord and the patient subsequently recovered complete function after $48 \mathrm{~h}$.

segment (Figure 3). There is good correlation with measurement between T1W and T2W sequences despite potential limitations with T2W images from cerebrospinal fluid (CSF) flow artefact, Gibbs artefact and chemical shift. ${ }^{16}$

The degree of cord compression has an important bearing on severity of cord injury, ${ }^{2}$ and the recording of both maximal canal stenosis at the injury site in addition to the degree of cord compression are proposed as important outcome measures by Fehlings ${ }^{17}$ linked to prognosis. Figure 4 outlines the method for calculation of degree of cord stenosis/compression.

\section{Cord oedema}

Cord oedema is detected as high T2 signal and normal/low T1 signal within the cord (Figure 5). It can also be associated with swelling of the cord (Figure 5). It has been shown that the length of oedema within the cord correlates both with the neurological presentation and outcome of the patient. $^{2}$ Patients with transient cord oedema where signal changes revert to normal on follow-up imaging also have a better outcome. Swelling of the cord is also associated with worse baseline American Spinal Injury Association motor scores, and is an independent poor prognostic indicator for 

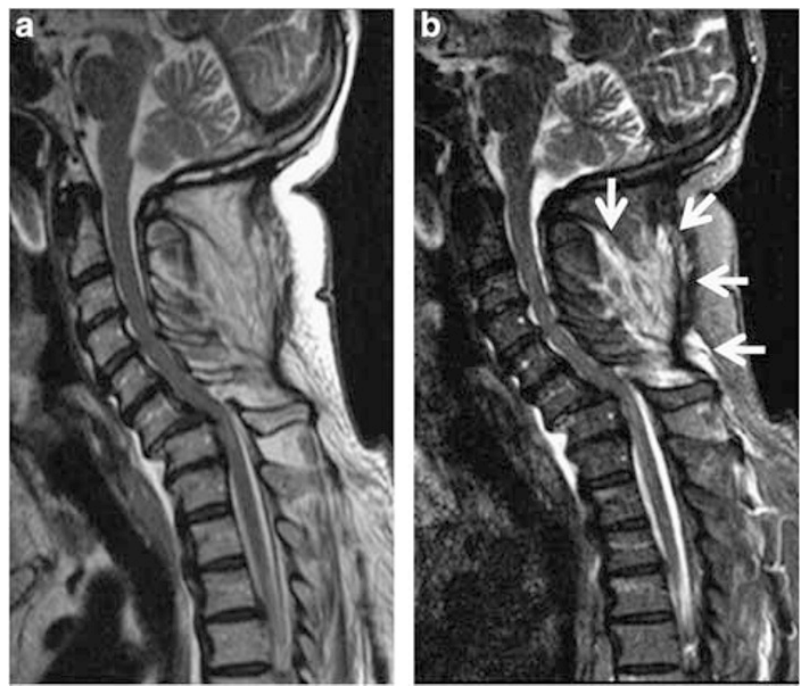

Figure 3 Cord compression. Following a diving accident this patient suffered from a traumatic fracture of the $\mathrm{C} 6 / 7$ vertebrae with cord compression (a) Sagittal T2W image demonstrates a bilateral facet joint dislocation at $\mathrm{C6/7}$ with anterolisthesis of $\mathrm{C} 6$ on $\mathrm{C} 7$ and compression of the cervical cord. There is no evidence of signal change within the cord yet. (b) The use of fat saturation in this sagittal Short Tau Inversion Recovery image demonstrates high signal within the soft tissues posterior to and around the spinous processes (white arrows) indicating substantial soft tissue and ligamentous injury. Note that this is not easily evident on the T2W image.
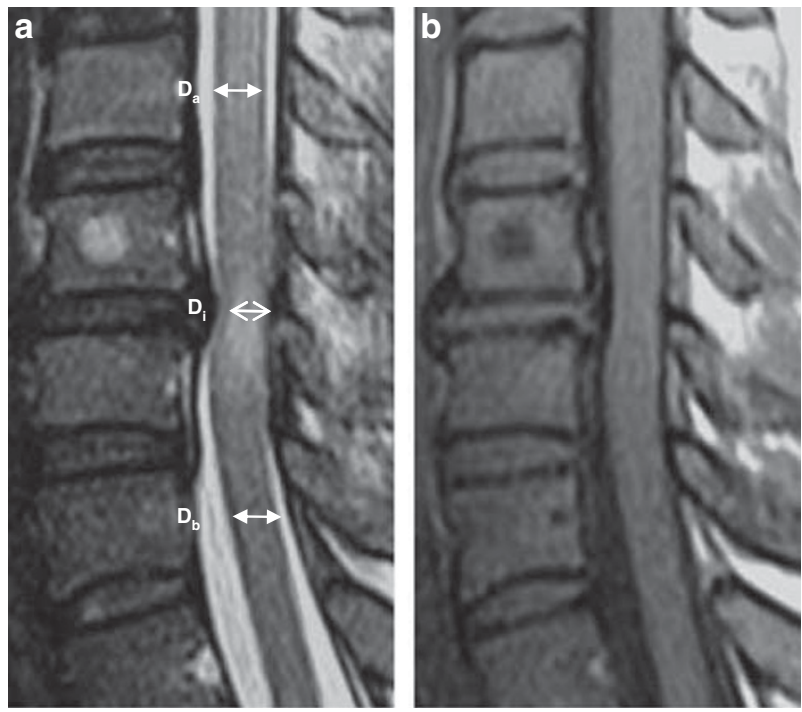

Maximum cord compression

$$
\left(1-\frac{D i}{D a+D b}\right) \times 100
$$

Figure 4 Maximum canal cord compression quantification. This patient fractured the cervical spine and injured the cord as the result of a motor vehicle accident. The images reveal a traumatic disc herniation, which had progressed following the original injury, worsening the degree of cord compression. (a) T2W and (b) T1W sagittal images seven days post injury. $D_{i}$ is the cord diameter at the level of maximum stenosis, $D_{a}$ is the cord diameter at the nearest normal level cranial to the stenosis, and $D_{b}$ is the cord diameter at the nearest normal level caudal to the stenosis. a
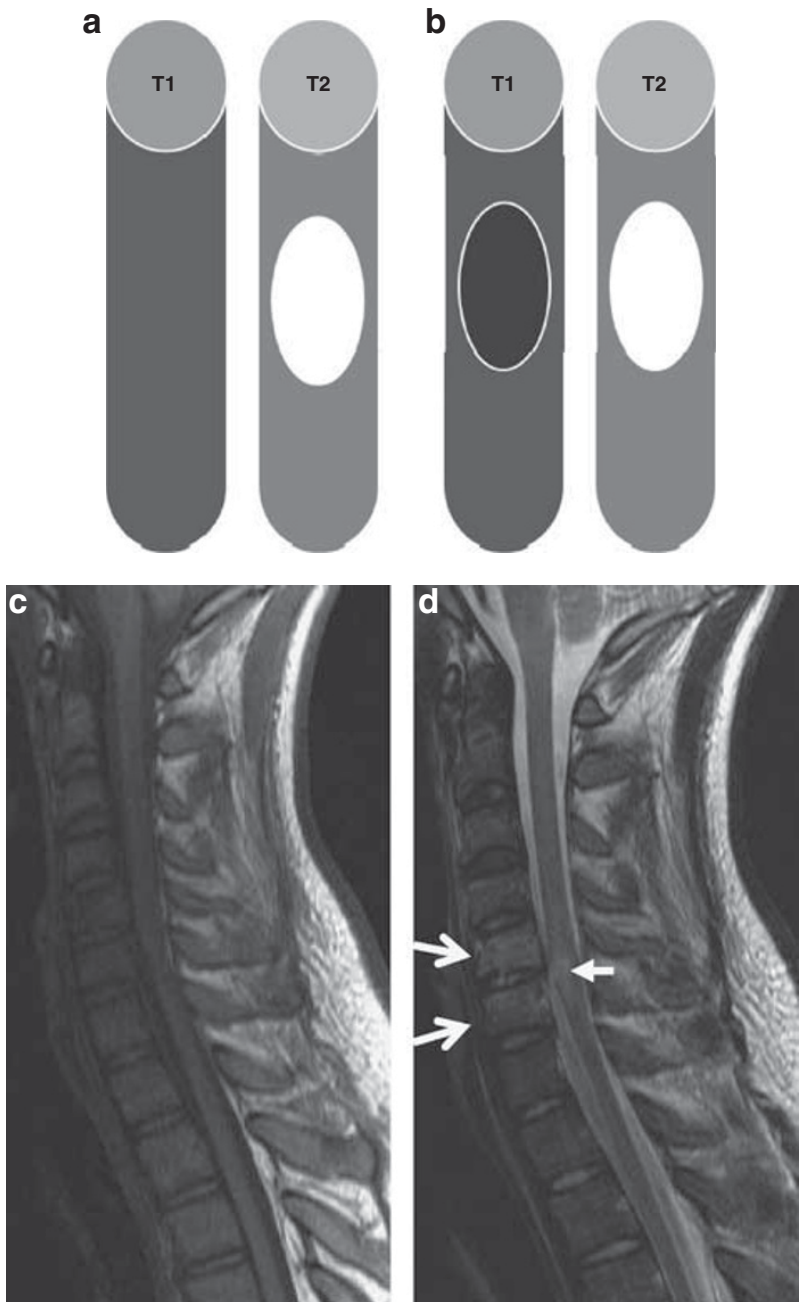

Figure 5 Cord oedema. (a) Schematic diagram demonstrating the imaging of oedema within the cord on T1W and T2W sagittal images. (b) In severe oedema or in later stages cavitation, the T1 signal becomes low. (c) No signal abnormality is demonstrated in the cord on the T1W images of this patient with a flexion-compression fracture of the cervical spine. (d) The T2W images demonstrate high signal in the bone marrow indicating oedema from vertebral fracture (open white arrows), and at the same level a localised area of cord swelling and high signal (closed white arrow). The short segment of involvement, lack of T1 signal change and absence of haemorrhage, puts this patient in a relatively favourable prognostic group.

neurological recovery when patients are standardized for their baseline scores on presentation. ${ }^{2}$

Cord oedema is not static and changes significantly within the first two weeks following injury (Figure 6). ${ }^{18}$

\section{Haemorrhagic contusion}

Cord contusion was defined by Kulkarni ${ }^{19}$ as a central intramedullary focus of low signal in the cord surrounded by a thick rim of hyperintensity on $\mathrm{T} 2 \mathrm{~W}$ or $\mathrm{T} 2{ }^{*} \mathrm{~W}$ GRE imaging (Figure 7). Gradient echo sequences should be used, as spin echo sequences may understate the degree of cord haematoma. The extent of haemorrhage within the cord has been correlated with outcome, with a small focus of haemorrhage of less than $4 \mathrm{~mm}$ more likely to be associated with radiological and clinical improvement on follow-up imaging, compared with a larger cord haematoma. ${ }^{20}$ 


\section{Cord haematoma}

Cord haematoma is a larger ( $>4 \mathrm{~mm}$ ) focus of intramedullary low signal with a thin rim of surrounding high signal on $\mathrm{T} 2 \mathrm{~W}$ or $\mathrm{T} 2{ }^{*} \mathrm{~W}$
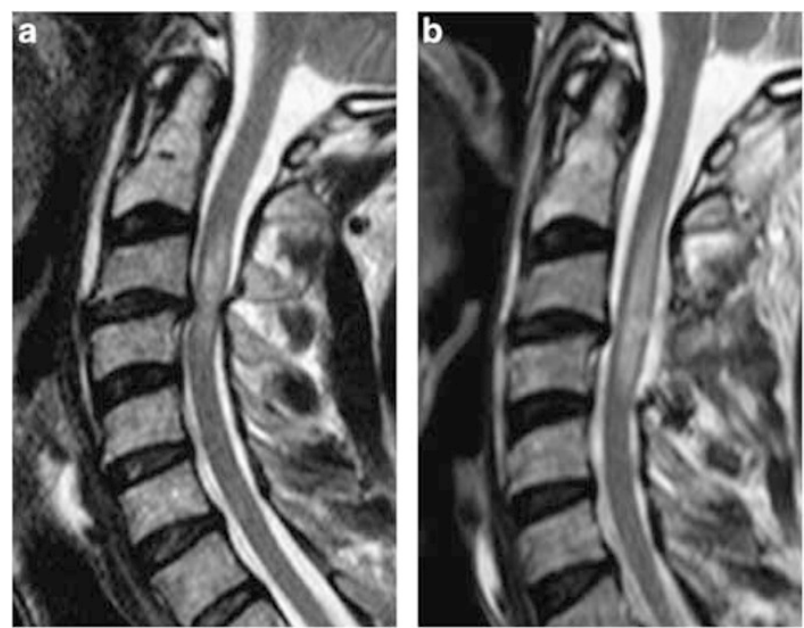

Figure 6 Changes in cord oedema. (a) Initial sagittal T2W image shows cord compression of the cervical cord with high signal change localised to the level of C3-4 indicating early cord oedema. (b) A repeat scan 3 days later demonstrates an increase in the length of the signal change in keeping with longitudinal extension of the cord oedema.
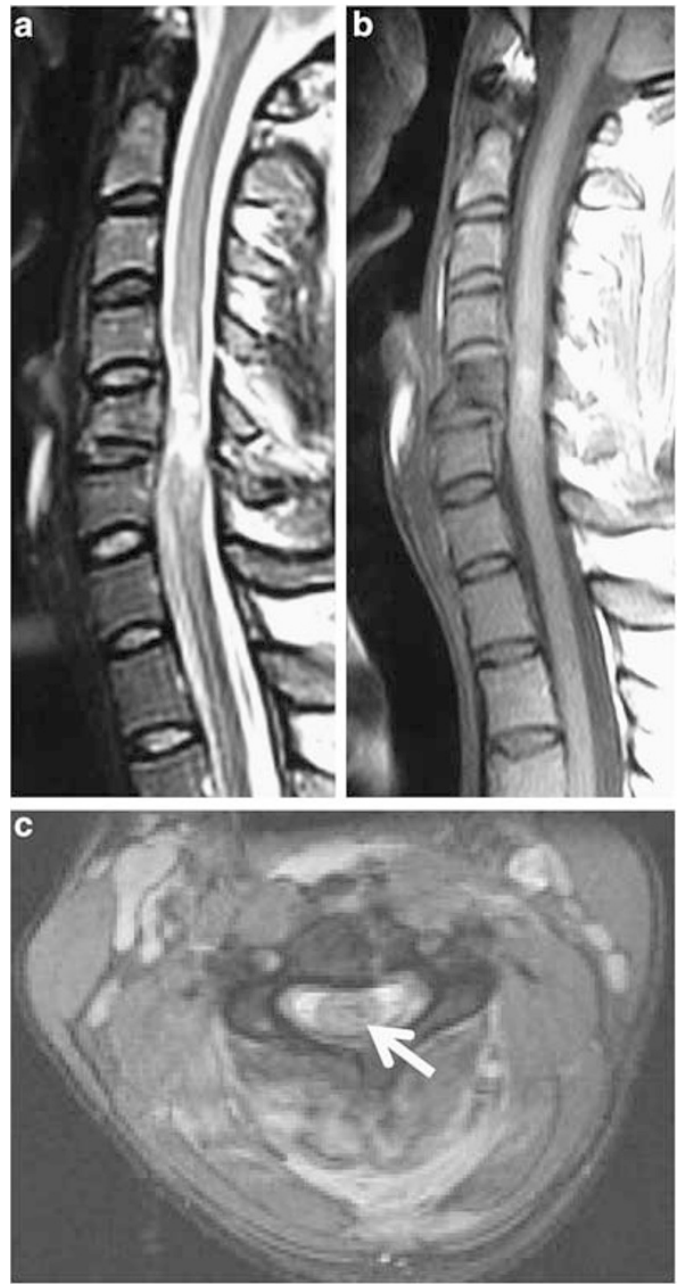

GRE imaging (Figure 8). There is good evidence from many studies that the presence of haemorrhage within the cord is associated with a poor neurological status on presentation, with patients more likely to have a complete SCI and worse baseline American Spinal Injury Association motor scores. ${ }^{2,7,19,21}$ In addition, the presence of cord haemorrhage is an independent poor prognostic indicator for neurological recovery even when patients are standardized for baseline scores. ${ }^{2}$

\section{Cord ischaemia}

Diffusion-weighted imaging is well-established in brain imaging but is more difficult to use in the cord due to the small volume of tissue, the CSF flow artefact and the inherent anisotropy of the cord tissue. Limited evidence is available in traumatic cord injury but preliminary results suggest that cord-restricted diffusion is linked to poor neurological recovery (Figure 9). ${ }^{22}$

Cord ischaemia is characterised in some cases by high T2 signal and cord enlargement. ${ }^{22}$ More recently, in a cohort of patients with incomplete cord injury where initial conventional MR sequences
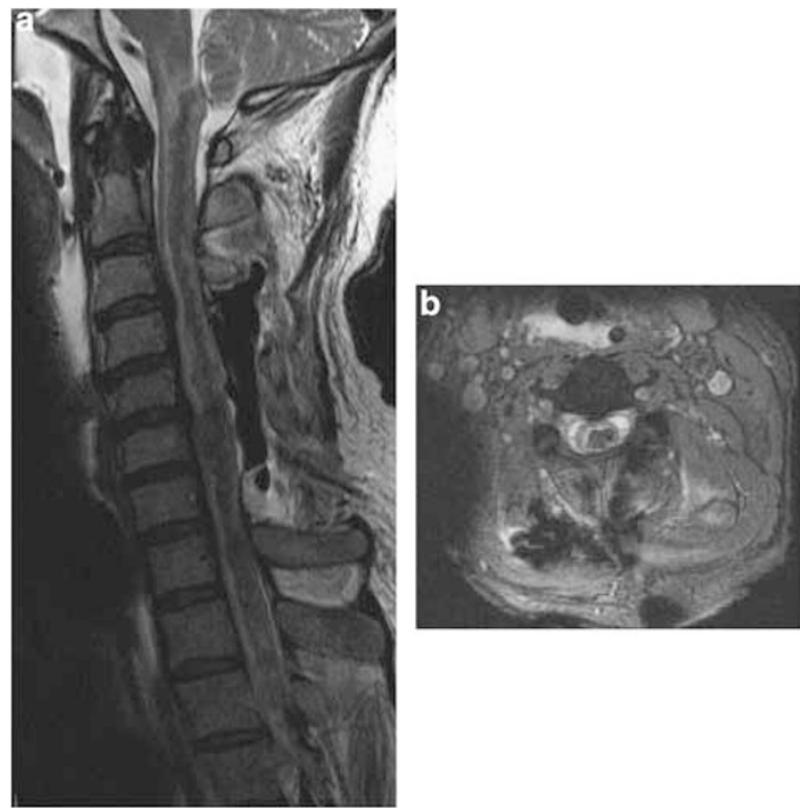

Figure 8 Cord Haematoma. This patient developed an acute deterioration of motor weakness, an ascending sensory level and decreased level of consciousness, $4 \mathrm{~h}$ after a decompressive laminectomy for spinal injury. The initial scan had demonstrated cord contusion and ongoing compression but only limited cord haemorrhage. (a) This sagittal T2W image from a repeat scan demonstrates the development of an extensive cord haematoma up to the level of the medulla oblongata, characterised by abnormal low signal throughout the cord with a thin rim of surrounding oedema. This is despite the absence of any ongoing cord compression. (b) Axial T2*W gradient echo sequences show the low signal haemorrhage centrally within the cord. The patient subsequently died from his injuries.

Figure 7 Haemorrhagic contusion. (a) T2W sagittal images demonstrate an area of high signal and cord swelling within the cervical cord at the C5 level. No low T2 signal is seen on this spin echo sequence to suggest haemorrhage. (b) However, T1W images demonstrate subtle increased signal indicating acute haemorrhage. (c) Axial T2*W gradient echo images confirm the presence of cord haemorrhage, with a subtle central area of low to intermediate signal (white arrow), thus demonstrating the increased sensitivity of gradient echo over spin echo for the detection of haemorrhage. 

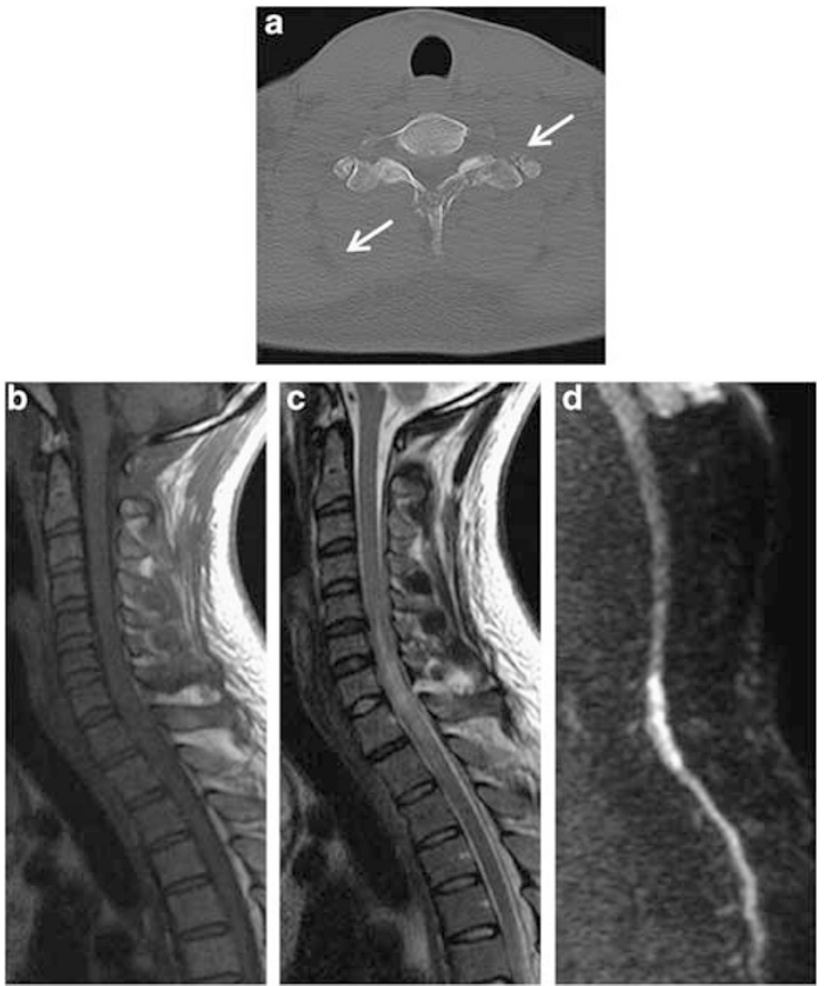

Figure 9 Cord ischaemia. (a) This patient was shot in the spine but the trajectory of the bullet missed the cord itself. This axial computed tomography image clearly depicts the trajectory and extent of bone injury (open white arrows). The entry point is at the fractured left transverse process of $\mathrm{C}$, passing through the fractured left $\mathrm{C} 7 / \mathrm{T} 1$ facet joint and left lamina, with the exit point near the midline of the vertebral column. The entry and exit wounds were small but detectable in the soft tissues of the neck. Sagittal T1W (b) and T2W (c) images demonstrate an area of high T2 signal in the cord but no tear, indicating injury is secondary to the close proximity of the blast force of the bullet rather than direct laceration. Diffusion-weighted imaging was performed and on this B1000 image (d) a focus of high signal intensity indicates an area of restricted diffusion in keeping with axonal injury.

have failed to show any abnormalities, diffusion-weighted imaging ${ }^{23,24}$ has demonstrated reduction in the apparent diffusion coefficient value in the transverse plane indicating restricted diffusion. ${ }^{25,26}$

Diffusion-weighted imaging remains a challenging technique but is now available on most MR systems. As hardware and software for these develop, it is likely to become a more useful clinical tool in the context of cord injury.

\section{Cord transection}

Cord transection is the most severe cord injury characterised by a complete disruption of the cord and high-signal CSF is seen between severed cord ends on the T2W images. It is a rare injury seen in extreme distraction and in penetrating injury (Figure 10). In penetrating injuries, it is possible that the cord may be significantly damaged with not much bone injury evident. In these cases, the cord injury is either due to a direct tear or secondary to blast injury from high-velocity mechanisms such as gun shots (Figure 9).

\section{SUBACUTE PERIOD}

Clinical issues that arise in the subacute period (typically 2-6 weeks following acute injury) include neurological deterioration and infec-
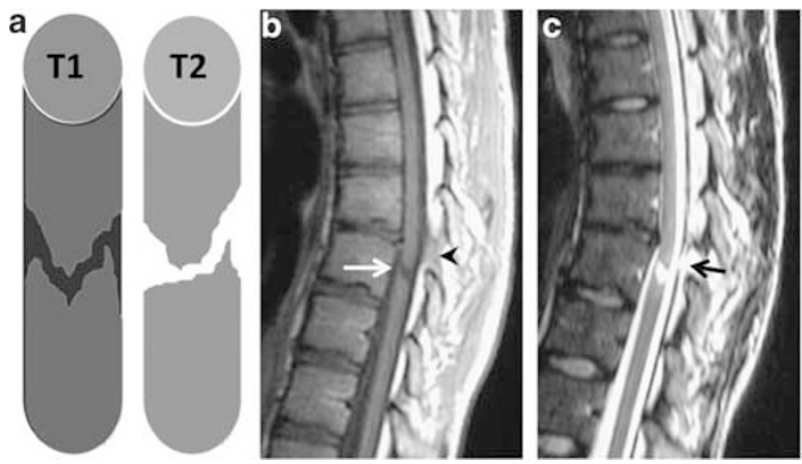

Figure 10 Cord transection. (a) Schematic diagram demonstrating the appearance of cord transection on T1W and T2W images. A young woman sustained a lap-belt flexion distraction injury during a head-on motor vehicle accident. T1W (b) and T2W (c) images demonstrate tears of the flaval ligaments (black arrowhead) and posterior dura (open black arrow). There is a partial rent at the same level in the cord (open white arrow). The cavity is filled with cerebrospinal fluid confirmed on both T1W and T2W images.
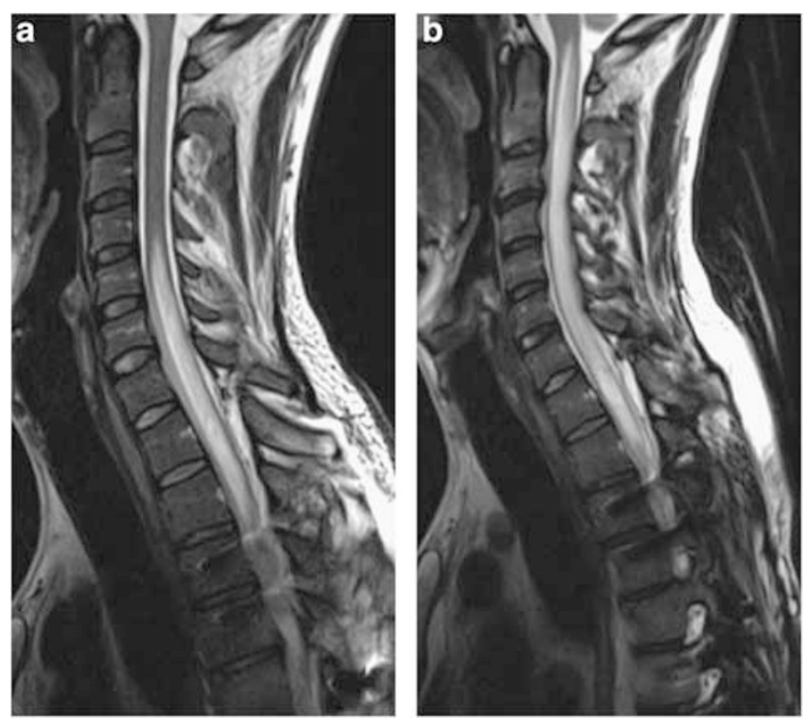

Figure 11 Subacute progressive ascending myelopathy. This patient developed a progressive deterioration of motor weakness (a) The initial sagittal T2W image demonstrated an extensive signal abnormality and prominent syrinx formation within the cervical and thoracic cord, extending inferiorly from the mid level of the C4 vertebral body to T7. Pedicle screw and plate fixation is seen between T3 and T4. (b) 6 months later, the signal change has now extended both cranially and caudally, and reaches the foramen magnum.

tion. Pain is more commonly neuropathic and assessed clinically rather than radiologically.

\section{Cord oedema}

Oedema changes significantly over time with initial progression rostrally by a segment ${ }^{18}$ in the first $48 \mathrm{~h}$, followed by regression over the subsequent 2 weeks (Figure 6). ${ }^{27}$ It may persist for up to 6 weeks, though usually improves significantly in this time.

\section{Subacute progressive ascending myelopathy}

A rare complication of SCI is subacute progressive ascending myelopathy, first described by Frankel in 1969, with an incidence of $2-6 \% .^{28,29}$ The clinical picture is typically one of deterioration in 
the patient's motor score and an ascending sensory level, although the condition can remain subclinical. This is also described as progressive posttraumatic myelomalacic myelopathy. The aetiology of this condition is debated but is likely to be due to altered CSF flow secondary to dural adhesions although ischaemic and inflammatory processes have been proposed. ${ }^{30,31}$ Imaging reveals a characteristic progression of oedema within the cord which extends more than four segments above the original injury and then typically subsides, but remains above the initial level (Figure 11). The signal abnormality is characteristically central with sparing of the cord periphery. Subacute progressive ascending myelopathy has an associated mortality of up to $10 \%$, although the majority of patients spontaneously improve but rarely regain all of the lost function. ${ }^{28}$ Lee et al. ${ }^{32}$ reported good recovery with cord untethering and duroplasty.

\section{Early syrinx}

Syrinx is defined as a fluid-filled intramedullary structure expanding above the injured segment with signal isointense to CSF. It is usually tapered at its cephalad and caudal extents. Its prevalence in chronic cord injury has been reported as up to $20 \%,{ }^{33}$ though symptomatic syrinx-like occurs in approximately $3 \%$ (Figure 8 ). ${ }^{34}$

Syrinx can occur within 2 months of injury but more commonly presents significantly later.

\section{CONCLUSION}

MRI is an essential tool to define the site and nature of cord injury in addition to associated disc, ligamentous and vertebral injuries. The MR appearances of cord haematoma, severity of maximal cord compression and length of cord oedema are all significantly associated with worse long-term functional independence scores and are important considerations in planning acute management.

Neurological deterioration in the subacute period is uncommon, but constitutes a medical emergency and MRI is pivotal in determining the underlying cause. Subacute progressive ascending myelopathy is a rare but important cause and MRI can easily differentiate this condition from other pathologies including epidural haematoma or delayed instability.

It is important that clinicians looking after the care of cord-injured patients become familiar with their MRI findings. In a time of rapidly evolving imaging techniques, close interdisciplinary liaison between radiologists and clinicians is essential to ensure that all specialties appreciate the clinical issues and the radiological-pathological correlation possible on MRI to optimise the best clinical outcome for this patient group.

\section{CONFLICT OF INTEREST}

The authors declare no conflict of interest.

1 Steeves JD, Lammertse D, Curt A, Fawcett JW, Tuszynski MH, Ditunno JF et al. Guidelines for the conduct of clinical trials for spinal cord injury $(\mathrm{SCl})$ as developed by the ICCP panel: clinical trial outcome measures. Spinal Cord 2007; 45: 206-221.

2 Miyanji F, Furlan JC, Aarabi B, Arnold PM, Fehlings MG. Acute cervical traumatic spinal cord injury: MR imaging findings correlated with neurologic outcome-prospective study with 100 consecutive patients. Radiology 2007; 243: 820-827.

3 Tewari MK, Gifti DS, Singh P, Khosla VK, Mathuriya SN, Gupta SK et al. Diagnosis and prognostication of adult spinal cord injury without radiographic abnormality using magnetic resonance imaging: analysis of 40 patients. Surg Neurol 2005; 63: 204-209.

4 Flanders AE, Schaefer DM, Doan HT, Mishkin MM, Gonzalez CF, Northrup BE. Acute cervical spine trauma: correlation of MR imaging findings with degree of neurologic deficit. Radiology 1990; 177: 25-33.
5 Schaefer DM, Flanders A, Northrup BE, Doan HT, Osterholm JL. Magnetic resonance imaging of acute cervical spine trauma correlation with severity of neurologic injury. Spine 1989; 14: 1090-1095.

6 Green RA, Saifuddin A. Whole spine MRI in the assessment of acute vertebral body trauma. Skeletal Radiol 2004; 33: 129-135.

7 Lammertse D, Dungan D, Dreisbach J, Falci S, Flanders A, Marino R et al. Neuroimaging in traumatic spinal cord injury: an evidence-based review for clinical practice and research. J Spinal Cord Med 2007; 30: 205-214

8 Bammer R, Fazekas F, Augustin M, Simbrunner J, Strasser-Fuchs S, Seifert T et al. Diffusion-weighted MR imaging of the spinal cord. Am J Neuroradiol 2000; 21 : 587-591.

9 Bammer R, Fazekas F. Diffusion imaging of the human spinal cord and the vertebral column. Top Magn Reson Imaging 2003; 14: 461-476.

10 Raya JG, Dietrich O, Reiser MF, Baur-Melnyk A. Methods and applications of diffusion imaging of vertebral bone marrow. J Magn Reson Imaging 2006; 24: 1207-1220.

11 Quencer RM, Bunge RP. The injured spinal cord: imaging, histopathologic clinical correlates, and basic science approaches to enhancing neural function after spinal cord injury. Spine 1996; 21: 2064-2066.

12 Berens SA, Colvin DC, Yu CG, Yezierski RP, Mareci TH. Evaluation of the pathologic characteristics of excitotoxic spinal cord injury with MR imaging. Am J Neuroradiol 2005; 26: 1612-1622.

13 Ohshio I, Hatayama A, Kaneda K, Takahara M, Nagashima K. Correlation between histopathologic features and magnetic resonance images of spinal cord lesions. Spine 1993; 18: 1140-1149.

14 Shimada K, Tokioka T. Sequential MRI studies in patients with cervical cord injury but without bony injury. Paraplegia 1995; 33: 573-578.

15 Shimada K, Tokioka T. Sequential MR studies of cervical cord injury: correlation with neurological damage and clinical outcome. Spinal Cord 1999; 37: 410-415.

16 Fehlings MG, Rao SC, Tator $\mathrm{CH}$, Skaf G, Arnold P, Benzel E et al. The optimal radiologic method for assessing spinal canal compromise and cord compression in patients with cervical spinal cord injury Part II: Results of a multicenter study. Spine 1999; 24: 605-613.

17 Fehlings MG, Furlan JC, Massicotte EM, Arnold P, Aarabi B, Harrop J et al. Interobserver and intraobserver reliability of maximum canal compromise and spinal cord compression for evaluation of acute traumatic cervical spinal cord injury. Spine 2006; 31: 1719-1725.

18 Leypold BG, Flanders AE, Burns AS. The early evolution of spinal cord lesions on MR imaging following traumatic spinal cord injury. Am J Neuroradiol 2008; 29: 1012-1016.

19 Kulkarni MV, McArdle CB, Kopanicky D, Miner M, Cotler HB, Lee KF et al. Acute spinal cord injury: MR imaging at 1.5T. Radiology 1987; 164: 837-843.

20 Boldin C, Raith J, Fankhauser F, Haunschmid C, Schwantzer G, Schweighofer F. Predicting neurologic recovery in cervical spinal cord injury with postoperative MR imaging. Spine 2006; 31: 554-559.

21 Silberstein M, Tress BM, Hennessy O. Prediction of neurologic outcome in acute spinal cord injury: the role of CT and MR. Am J Neuroradiol 1992; 13: 1597-1608.

22 Nedeltchev K, Loher TJ, Stepper F, Arnold M, Schroth G, Mattle HP et al. Long-term outcome of acute spinal cord ischaemia syndrome. Stroke 2004; 35: 560-565.

23 Loher TJ, Bassetti CL, Lovblad KO, Stepper FP, Sturzenegger M, Kiefer C et al. Diffusion-weighted MRI in acute spinal cord ischaemia. Neuroradiology 2003; 45: 557-561.

24 Fujikawa A, Tsuchiya K, Takeuchi S, Hachiya J. Diffusion-weighted MR imaging in acute spinal cord ischemia. Eur Radiol 2004; 14: 2076-2078.

25 Kuker W, Weller M, Klose U, Krapf H, Dichgans J, Nagele T. Diffusion-weighted MRI of spinal cord infarction-high resolution imaging and time course of diffusion abnormality. J Neurol 2004; 251: 818-824.

26 Thurnher MM, Bammer R. Diffusion-weighted MR imaging (DWI) in spinal cord ischemia. Neuroradiology 2006; 48: 795-801.

27 Gonzalez CM, Matheus G, Solander S, Castillo M. Transient edema of the spinal cord as a result of spontaneous acute epidural hematoma in the thoracic spine. Emerg Radiol 2004; 11: 53-55.

28 Planner AC, Pretorius PM, Graham A, Meagher TM. Subacute progressive ascending myelopathy following spinal cord injury: MRI appearances and clinical presentation. Spinal Cord 2008; 46: 140-144.

29 Frankel HL. Ascending cord lesion in the early stages following spinal injury. Paraplegia 1969; 7: 111-118.

30 Aito S, El Masry WS, Gerner HJ, Lorenzo ND, Pellicano G, D'Andrea M et al. Ascending myelopathy in the early stage of spinal cord injury. Spinal Cord 1999; 37: 617-623.

31 Schmidt BJ. Subacute delayed ascending myelopathy after low spine injury: case report and evidence of a vascular mechanism. Spinal Cord 2006; 44: 322-325.

32 Lee TT, Arias JM, Andrus HL, Quencer RM, Falcone SF, Green BA. Progressive posttraumatic myelomalacic myelopathy: treatment with untethering and expansive duraplasty. J Neurosurg 1997; 86: 624-628.

33 Wang D, Bodley R, Sett P, Gardner B, Frankel H. A clinical magnetic resonance imaging study of the traumatised spinal cord more than 20 years following injury. Paraplegia 1996; 34: 65-81.

34 Rossier AB, Foo D, Shillito J, Dyro FM. Posttraumatic cervical syringomyelia. Incidence, clinical presentation, electrophysiological studies, syrinx protein and results of conservative and operative treatment. Brain 1985; 108 : 439-461. 